\title{
LA DIMENSIÓN SOCIOLÓGICA DEL ARTE MUSICAL
}

\author{
The Sociological Dimension of Musical Art
}

\author{
George Velazco Agramonte ${ }^{1}$
}

\begin{abstract}
RESUMEN
El arte musical puede observarse desde perspectivas muy diferentes. La más habitual es la de considerar la música como arte. Un even to artístico, un concierto es un acto musical, pero también es un acto social; según los contextos puede ser también un acto de afirmación de sentido de tiempo, espacio, generacional, clase, etnicidad y género. En esta dimensión ya no consideramos a la música solo como un arte sino como un acto social capaz de generar y articular realidades sociales; lo que la convierte en variable independiente frente a las realidades sociales.
\end{abstract}

Palabras clave: Adscripción, espacio, etnicidad, desarrollo, organización, tiempo, simbolismo, valores einterdisciplinariedad.

\section{ABSTRACT}

The musical art can be seen from very different perspectives. The most common is to consider music as art. An artistic event, a concert is a musical act, but also a social act; depending on the context it can also be an act of affirmation of time sense, space, generational, class, ethnicity and gender. In this dimension we not only consider music as an art but as a social event that can generate and articulate social realities; making art as an independent variable against social realities.

Keywords: Ascription, space, ethnicity, development, organization, time, symbolism, values and interdisciplinarity.

\section{INTRODUCCIÓN}

Siempre ha habido música, y no conocemos a ninguna sociedad que, de una u otra manera, no desarrolle algún tipo de actividad que pueda ser calificada de musical. ¿Por qué se presume tan a menudo la existencia de músicas que resuman esencialismos nacionalistas? ¿Por qué algunas músicas se codean con el whisky y otras lo hacen con el vino de misa o licores baratos? ¿Por qué hay unos géneros o estilos musicales que atraen más que otros? No es tan sólo por razones de excelencia musical, por cuestiones de marketing, de tradición o forma de difusión. Todos estos factores mencionados son, sin lugar a dudas, importantes. Creemos que son cuestiones que más de un melómano se habrá hecho alguna vez; y en música, como fenómeno sociocultural, resulta perti-

\footnotetext{
${ }^{1}$ Doctor en Ciencias Sociales, Magister en Artes, Licenciado en Artes. Docente de la Facultad de Ciencias Sociales, Escuela Profesional de Arte, Especialidad de Música, Universidad Nacional del Altiplano. Puno-Perú.

Correoelectrónico:jorgeva77@hotmail.com
} 
nente plantearse estas problemáticas.

Este es precisamente el gran poder de la música, poder hablar de todo sin decir nada. La música es portadora de mensajes, a pesar de que no siempre vaya acompañada de palabras y en ellas mensajes conductistas. No es preciso que sea portadora de palabras para que sepamos a qué se está refiriendo: sentimientos nacionalistas expresados a través de repertorios tradicionales, mística religiosa o la música sufí, etc.

A pesar de su diversificación aparente, tienen una base común: los procesos de creación de categorías sociales a partir de las cuales entendemos la realidad y las relaciones entre individuos que lograremos desarrollar y reflexionar a partir de una perspectiva interdisciplinaria que sin duda conciernen a la música, a la antropología y a la sociología.

\section{LA MÚSICA Y LA CONSTRUCCIÓN SOCIAL DE LA REALIDAD}

Joseph Martí Í Pérez (2000), encontró que "una sociedad sin música nos resulta inimaginable. Sus creencias, sus sueños, sus carencias, sus maneras de entender el mundo y de entroncarse en él toman forma a través de este omnipotente magma sonoro" (p.9).

En efecto, la música no constituye un arte atemporal y socialmente descontextualizado, sino que es una práctica artística que cumple siempre funciones muy concretas dentro de la sociedad. De acuerdo con esta idea, la música no refleja tan sólo el espíritu de una época, sino también interviene dialécticamente en la configuración de ese espíritu. Sin duda escuchamos música, hablamos de música, y los poderosos medios de comunicación figurarán siempre como su eterno aliado. Pero, en realidad, la importancia que le otorgamos es apenas comparable a la enorme importancia social del mundo de la política o de la economía. Se concibe básicamente la música como diversión o, en ocasiones, también incluso como algo ciertamente elevado pero que al fin $y$ al cabo constituye un lujo social. También conocemos la poca importancia que nuestro sistema educativo tradicionalmente ha otorgado a esta materia, y sólo dentro del ámbito de las denominadas actividades protocolares, se le concede cierto protagonismo. A pesar de que su espacio natural no se limita a las convencionales salas de conciertos. Su presencia invade nuestros hogares, los largos corredores del metro, el interior de nuestro automóvil, las iglesias, los grandes almacenes. "Hay que aprender a juzgar una sociedad por sus ruidos, por su arte y por su fiesta más que por sus estadísticas".

De esta manera la importancia social de la música se convierte en un hecho muy evidente, porque con su gran poder de convocatoria, es capaz de expresar maneras de pensar, y de articular colectivos humanos, otorgando a las personas sentidos de adscripción y pertenencia.

\section{La música y el sentido del tiempo}

Para el joven, la música es tremendamente importante porque le abre el camino de entrada a la sociedad: le da sentido del tiempo. Es decir, le explica el mundo en el cual vive, le marca los roles que ha de desempeñar en la sociedad, como adolescente, primero, y como adulto después. Es decir, la necesidad entre los jóvenes de hallar su propia identidad para poder entenderse dentro de un tiempo diferenciado de la de sus progenitores, deberá jugar un papel muy importante la configuración de sus propios gustos musicales.

\section{La música y el sentido del espacio}

La música da también sentido del 
espacio en el cual nos sentimos circundados. Las denominadas músicas tradicionales constituyen uno de los típicos recursos para expresar musicalmente la idea de una localidad concreta. También las músicas populares actuales dan a los jóvenes puntos de referencia de su espacio. Hoy vivimos en lo que acertadamente se ha denominado aldea global.

\section{La música y el sentido generacional}

El arte de combinar los sonidos da también sentido generacional. Es decir, existen repertorios y géneros que podemos calificar de infantiles, juveniles o de gente mayor. Estas músicas incorporan rasgos que nosotros consideramos característicos para los diferentes grupos de edad. Por ejemplo, Las músicas infantiles nos sugieren aparentemente sencillez e ingenuidad. Las músicas jóvenes adoptan a menudo actitudes rebeldes como bandera. Las que adscribimos a la población más madura, refugiándose en estilos melódicos, expresan tranquilidad, un velado deseo de no querer complicar las cosas, puesto que la vida les ha enseñado que, en este mundo, todo ya es por naturaleza suficientemente complicado. Hay que agregar la música que contiene letras, y con ello, no es tan sólo estética sino tambiénética.

\section{La música y el sentido de clase}

También el arte musical da sentido de clase. A algunas músicas las relacionamos con lujosos teatros, mientras que a espacios menos formales, pero finalmente ambos espacios son por naturaleza colectivos. Hay músicas elitistas y también urbanas populares. Así por ejemplo hay músicas que exigen la corbata y los abrigos de pieles, mientras que otras, los polos y jeans usados.

\section{La música y el sentido de etnicidad}

La música otorga sentido de etni- cidad. La etnicidad constituye todavía hoy en día un importante factor de adscripción grupal, y son muchos los jóvenes y no tan jóvenes los que experimentan este sentimiento de pertenencia social a un grupo que va más allá de la familia o de los vecinos de nuestro lugar de residencia a través precisamente de la música.

\section{La música y el sentido de género}

Lo mismo podemos decir en cuanto al género, es decir, en cuanto a los diferentes roles relacionados con el sexo de hombres y mujeres de nuestra sociedad. Todos sabemos la existencia de famosas sopranos, expertas profesoras de piano o de directoras de orquesta y compositoras. Todo ello forma parte de una sólida ideología que manifestada a través de nuestras prácticas musicales contribuyen también al mantenimiento de las estructuras sexistas de la sociedad (Martí Í Pérez, 2000).

De manera muy escueta, hemos citado y hablado de tiempo, espacio, generación, clase, etnicidad y género; sin embargo, creemos que asimismo son importantes para la identidad de la persona la religión, adscripción profesional, formación académica, etc. Con todo esto tampoco pretendemos decir que cualquier persona tenga que encontrar estos sentidos en las músicas que escucha y por las cuales se desvive a diario. Pensamos que el arte musical da respuestas sobre todo a quien le hace preguntas.

Debemos agregar que al escuchar una determinada música, es posible que ésta nos sugiera la necesidad de formularnos ciertas cuestiones que, si no la hubiésemos escuchado, quizás no nos las habríamos formulado. De aquí también la gran fuerza social de la música y el deseo de su control por las estructuras de poder, ya que con la música nació el poder y su contrario, la subversión. La 
música no es siempre algo inocuo $\mathrm{y}$, evidentemente, no todo rechazo a una música implica solamente consecuencias intrínsecamente musicales.

Sin embargo, la música, especialmente la popular, es para los jóvenes una ventana abierta al mundo, y que uno de los objetivos de las estructuras de poder es colocar una cortina de humo más o menos opaca, y de acuerdo a sus intereses, a esta ventana. También que los sistemas políticos y religiosos, no dudan en ejercer poderosos intentos de control selectivo para la música de su población o de sus adeptos. Lo hemos visto con especial virulencia en los regímenes totalitarios europeos, en la China comunitaria o en ciertos ámbitos del mundo musulmán. De otra forma, ciertos grupos de cristianos fundamentalistas han expresado un rechazo rotundo a determinados tipos de rock como también lo hacen los integristas islámicos en relación a la música occidental. Los sistemas no tienen tan sólo sus músicas preferidas, sino también sus músicas rechazadas, pero los músicos también pueden resultar incómodos para el sistema incluso en nuestras actuales democracias.

Una de las características de la música viva de amplia aceptación por parte de la sociedad es su inmediatez en relación al ámbito social en el cual se produce. Es decir, que no exista distancia entre las experiencias sociales expresadas por la música y las experiencias propias del público. Esto se refleja a la perfección en los temas y letras de las canciones de músicas populares en los que se habla de todo aquello que interesa o forma parte de la vida cotidiana de cualquier joven. Por tanto, a la fuerza tenemos que pensar que todo cambio que se produzca en la sociedad se reflejará también en la producción musical. Y todavía más, que muchos cambios que se producen en la sociedad son incluso anunciados por la música antes de que éstos se produzcan, sencillamente porque la música es portadora de ideas y sentimientos que en un futuro próximo provocarán cambios sociales.

La tarea de conocer el arte musical, no constituye una tarea sencilla; no por la complejidad del fenómeno en sí, sino porque muchos de los recursos humanos son en su naturaleza a veces diferentes a los que tenemos para pensar sobre ella o intentar entenderla. La músi$\mathrm{ca}$, y siempre que la queramos entender como algo que va más allá de sus intrínsecas propiedades acústicas, ha surgido de nuestras estructuras sociales, las mismas al fin y al cabo con las que intentamos analizarla. Por ello no resulta siempre fácil pretender conocer este medio en el cual nos movemos, y por tanto, no nos tiene que extrañar en absoluto que sea a través de una óptica interdisciplinaria la manera más indicada de hacerlo, en este caso analizando los usos y funciones sociales.

\section{USOS Y FUNCIONES SOCIALES DEL ARTE MUSICAL}

Merriam (1964) encontró que sin duda uno de los temas más importantes dentro de cualquier sociedad que involucre la participación de la música es el de precisar y diferenciar los usos y funciones que cumple ésta en la sociedad en general y, cómo no, también a nivel individual. Ahora al estudiar la música como generadora de realidades sociales no basta con hacer un estudio descriptivo de los acontecimientos relacionados con la música, sino que hay que delinear además su significación. Para esto es necesario precisar no solo qué es la música sino además qué significa para las personas y de qué forma les afecta, directa o indirectamente. 


\section{De los usos sociales de la música}

Pensamos que las personas usan, emplean, utilizan la música de diversas formas. Por ejemplo, una serenata tiene un uso específico dirigido hacia una persona o grupo de personas. Al respecto Merriam (1964) piensa que, cuando hablamos de los usos de la música, nos referimos a las formas en que se emplea o se utiliza la música en las sociedades humanas, a la práctica habitual o ejercicio de costumbre de la música como algo en sí mismo o en conjunción con otras actividades. La música puede utilizarse en varias situaciones, tiene varios usos, que pueden tener una función social significativa o no.

\section{De las funciones sociales de la música}

Pensamos que las personas emplean la música para conseguir algo. Por ejemplo las serenatas tenían la función de expresar amor, comunicación pública de expresar un contenido, comportamiento grupal (entendimiento colectivo, relación e interacción colectiva). Al respecto, Radcliffe-Brown (1952), afirma que la función es la contribución que tiene una actividad sobre la actividad total. Que la función de un uso social es la forma en que contribuye al funcionamiento de la vida social. Este punto de vista implica que un sistema social está compuesto por un cierto tipo de unidades, unidades funcionales que trabajan unidas con un grado suficiente de armonía o consistencia interna, sin producir conflictos persistentes que no puedan ser solucionados.

Acerca de usos y funciones, Alan Merriam (1964) formula dos preguntas clave que nos pueden ayudar a diferenciarlos: para los usos: ¿cómo utilizo la música? y para las funciones: ¿para qué utilizo la música? Finalmente, ningún elemento cultural más ofrece la oportunidad de expresión emocional, entrete- nimiento, comunicación, validación contribución, etc., en el grado que lo hace la música, debido a que la música es una actividad sumatoria para la expresión de valores, un mecanismo por medio del cual se expresa la esencia de la psicología de una cultura sin los artefactos protectores que rodean otras actividades culturales. Como vehículo de transmisión de la historia, mitos y leyendas, supone la continuidad de la cultura; a través de su enculturación y educación contribuye a la estabilidad de la misma.

\section{UNA VISIÓN SOCIAL - GLOBAL DEL ARTE MUSICAL}

Dentro del ámbito social de la música, se usan con frecuencia los términos texto y contexto en un justificable deseo de querer superar el protagonismo desmedido dado al texto. Pero una visión holística de cualquier objeto de estudio lleva implícita la idea de sistema, aspecto que nos puede ser de suma utilidad, como estrategia metodológica, al aplicarlo al fenómeno musical de una cultura dada. Según esta perspectiva, Joseph Martí Í Pérez (2000) encontró que se puede establecer una estrategia analítica que se adecue a los fines de cada investigador pero supeditándola obviamente a la idea del arte musical como un todo orgánico donde, desde la perspectiva de un marco metodológico se podía lograr una posibilidad que garantizaría una cierta integridad de la visión sobre un sistema musical dado estableciéndose tres niveles de análisis social:

\section{El nivel social fenomenal}

Este nivel de análisis englobaría todos aquellos fenómenos claramente perceptibles por el investigador que, para ser constatados no requieren más que la observación. Encontraríamos unos actores sociales, analizables tanto 
desde el punto de vista de la (re) creación (músicos) como de la recepción (contexto-público). La idea central de este nivel lo constituye el evento musical. El concepto es generalizador, no importa el tipo de música, ni el tipo de ejecución, ni la finalidad con que se realiza. La idea de evento musical es útil porque por una parte nos ayuda a calibrar la relevancia social de una música al margen de los criterios más estandarizados de apreciación como es el prestar atención a los fenómenos de más clara institucionalización, como son, por ejemplo, los conciertos, recitales, etc. Un concierto es un evento musical, así como lo es el canto de los niños en su escuela, el silbar o el uso de radios individuales que el caminante acompaña de esta manera sus pasos en solitario.

Por otra parte, debido al drástico cambio a causa del desarrollo de la industria del sonido. En la actualidad, en nuestra sociedad se canta menos que antes, no obstante, esto no significa que la música haya perdido importancia. Sencillamente, la relación del individuo con el medio musical es diferente, porque también lo son sus recursos. Las personas canturreaban mientras se dedicaban al realizar sus faenas; sin embargo, hoy una radio le ofrecerá el entretenimiento musical. Fue muy habitual que en grupo de jóvenes hubiese alguien que supiera tocar la guitarra con la que se acompañaba el repertorio de las canciones del grupo. Hoy por ejemplo, es el equipo de música aquello que remplaza esta función. Estructuralmente estas situaciones de antes y después no son tan diferentes, ya que existe un uso musical con unas finalidades que no han cambiado; en unas hay una producción musical real en las otras todo se limita a un mero consumo pasivo.

\section{El nivel social ideacional}

Este segundo nivel ya no resulta accesible mediante la observación sino que requiere la indagación por parte del observador. Está constituido por el mundo ideacional del sistema, es decir, el conjunto de ideas que desde una perspectiva holística justifican la existencia de cada uno de los fenómenos observables en el primer nivel (fenomenal). Dentro de este ámbito tendríamos que hablar de la significación, el simbolismo del conjunto de normas y valores que configuran el mundo musical. Debemos tener en cuenta la teoría musical, así como las ideas de gran y pequeña historia. La gran historia viene dada sencillamente por los discursos oficiales que se formulan sobre un hecho musical, mientras que la pequeña historia es aquello que se dice pero que generalmente no está sancionado por la historia oficial, aunque en ocasiones puede incluso ser también acríticamente asumido por ésta.

$\mathrm{Si}$ en el nivel fenomenal el evento musical ocupa un espacio central, la idea de narrativa cumple la misma función para el caso del nivel ideacional. Este discurso narrativo es uno de los sistemas de entendimiento más importantes que usamos para dotar de sentido a nuestra realidad. Los eventos aislados que conforman nuestra realidad son transformados por medio de las narrativas en episodios unidos por una trama argumental; es decir, la trama argumental que proviene de las canteras de un pueblo (pequeña historia) es la base de una suerte de ordenamiento de la construcción de la historia formal (gran historia). De esta manera un mismo hecho objetivo puede ser visto de maneras muy diferentes (incluso contradictorias) por parte de los actores sociales. Un ejemplo, cuando se habla de las danzas que se miran, escuchan, ejecutan, y/o bailan en carnavales es muy fácil entenderla desde 
fuera como fenómeno étnico y con carácter representativo para una sociedad. Pero el entramado semántico propio de la realidad carnavalesca es realmente mucho más complejo que una simple observación descontextualizada.

De todo esto podemos deducir que para unos, el bailar en carnavales representa un acto de afirmación nacionalista, para otros alude, por el contrario, a un tibio regionalismo. Mientras que para unos bailar constituye un acto popular y democrático (por tanto abierto a todo el mundo), para otros, es algo propio de los del lugar. Mientras unos ven la danza sana y moral, otros la ven irremediablemente atávica y cursilona. Mientas que unos consideran una actividad plenamente participativa, otros la consideran aburrida e insulsa. Mientras que unos se niegan a identificarla como danza folclórica y le otorgan el carácter de danza popular, para otros no existe ninguna diferencia entre ella y la otra. Mientras que para unos los carnavales se identifican con el contexto festivo, para otros esta misma actividad no es sino el resultado de la inercia y rutina administrativa de las comisiones de fiestas de los pueblos y ciudades.

\section{El nivel social estructural}

Para comprender este nivel de análisis ya no bastarían la observación y la indagación sino que el investigador debería deducirla mediante la elaboración de las informaciones conseguidas de los primeros niveles y las relaciones que pueda establecer con el sistema sociocultural general. Este nivel lo forman aquellos "elementos sistémicos" de los cuales los actores pueden ser o no conscientes; estos elementos son los que, en definitiva, permiten que el sistema funcione. En este nivel de análisis encontramos los fenómenos relativos a la enculturación que deben ser distinguidos del simple aprendizaje, es decir que mientras que el aprendizaje constituye siempre un acto consciente y dirigido generalmente de tipo vertical, la enculturación implica la asunción de los contenidos culturales de la propia sociedad tanto de manera consciente como inconsciente, es decir, vertical y horizontal.

Los aspectos funcionales de las prácticas musicales deben ser incluidos también en este tercer nivel, así como las relaciones que se establecen entre el sistema musical estudiado con los medios de producción económica o simbólica, con las estructuras de poder (política) de la sociedad, etc. Este estudio requeriría un tratamiento predominantemente de la idea de función y finalidad, donde los actores del sistema sociocultural no son siempre conscientes de las funciones de los diferentes elementos de la cultura. Es decir, función se refiere al papel consciente o inconsciente que cualquier elemento de la cultura juega dentro del sistema sociocultural, es decir, la "contribución que aporta una actividad parcial a la actividad total de la que forma parte". La finalidad, en cambio, pertenece a las categorías que implican siempre conocimiento y volición.

$\mathrm{Al}$ respecto, un tratamiento diacrónico podría delinear el cambio y la historia. (Ver figura 1).

Este modelo epistemológico apenas esbozado implica un artificioso seccionamiento del ámbito de estudio con fines analíticos sin olvidar, no obstante, que estas diferentes secciones se encuentran íntimamente relacionadas y que atañe al investigador establecer estas relaciones. El holismo conlleva precisamente un proceso de síntesis creadora. Tener conciencia de la interrelación existente entre pautas fenomenales, pautas ideacionales, pautas estructurales (procesos dinámicos) que caracterizan a un sistema vivo-abierto, como es el caso del 
Nivel estructural: "Elementos sistémicos"

- Función

- Enculturación

- Transmisión

- Relación con los medios de producción

- Relaciones de poder

- Correspondencias con estratos de población

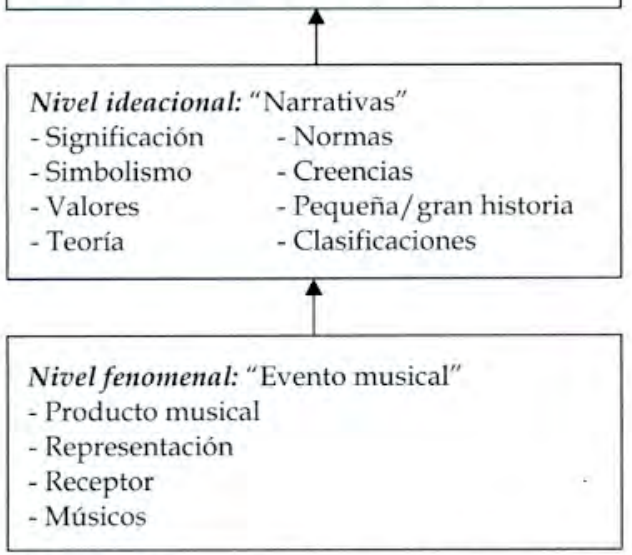

Figura 1. Esquema de niveles de análisis social de la música.

arte musical entendida en este caso como acto u evento social.

Estas diversas combinaciones de elementos procedentes de niveles de análisis constituyen los núcleos sistémicos a través de los cuales se articula el fenómeno musical. Sería ingenuo pensar que desde el punto de vista sociocultural, un tipo determinado de música viene solamente configurado por su materia musical. Con todo esto queda bien claro que las cuestiones que interesan al investigador musical que trabaje según la perspectiva holística son de naturaleza múltiple y muy complejas. Esta perspectiva es sumamente integrativa ya que partiendo del principio de que las relaciones entre los diferentes eventos son tan importantes como la naturaleza de estos mismos eventos, se intenta entender cómo los diferentes aspectos de la cultura y de la sociedad se relacionan entre ellos. Con ello se da, así mismo, la debida importancia a los aspectos procesuales de la dinámica cultural (y musical). Las produccio- nes musicales constituyen un conjunto de sonidos organizados y la tarea del investigador consiste en elucidar los mecanismos sociales que rigen esta organicidad, ya se trate tanto de aspectos de orden estrictamente musical como de orden sociocultural en el sentido más amplio del término.

\section{EL FOLCLORE Y EL DESARROLLO SOCIAL}

Lourdes Méndez (2009) cuando habla del arte primitivo al arte contemporáneo menciona que "el Folclore es una disciplinà histórico-proyectiva que estudia cosas vivas venidas de tiempos pasados, pero las estudia no para regodearse en tal contemplación de ellas o con un examen sistemático quedarse allí, sino para junto con otras disciplinas (interdisciplinariedad) contribuir al desarrollo sostenible de una sociedad". En este sentido, el desarrollo social es el salto de una fase determinada a otra cualitativamente superior. Ahora bien, este desarrollo que también contempla aspectos culturales, pueden adelantarse o retrasarse. Se retrasa generalmente por el poco desarrollo productivo de la sociedad y adelanta con el desarrollo del mismo, con la participación productiva, madura y equilibrada de la sociedad y sus agentes.

Como ya se dijo si el Folclore es una disciplina histórica-proyectiva que estudia el patrimonio de un pueblo, si el desarrollo social es un paso tajante y necesario de una sociedad que puede adelantarse o retrasarse en su advenimiento y si el patrimonio popular (cultura) es parte de la producción, maduración y equilibrio social: el vínculo entre Folclore y desarrollo social se hace muy visible. De tal manera que, el correcto manejo del patrimonio tradicional de un pueblo puede contribuir, y contribuye, al acele- 
ramiento del proceso y desarrollo; el incorrecto manejo obviamente, a su retraso. Una sociedad es única pero también es parte de la humanidad; una humanidad que se enriquecerá con sus peculiaridades y se deleitará auténticamente con ellas.

De otro lado la evolución tecnológica y el incremento en el tamaño demográfico de las sociedades no pueden tomarse como signos de la evolución de la cultura en general, ni del potencial intelectual humano. Es decir, una canción popular/folclórica africana o sudamericana no es necesariamente menos intelectual que una sinfonía: la aparente simplicidad de sus sonidos pueden esconder complejos procesos en su generación; pudo haber sido estimulada por un salto intelectual hacia delante, en el cual, quien la compuso vio más allá de los límites de su cultura y fue capaz de inventar una forma nueva $y$ poderosa para expresar en sonidos su visión de las posibilidades ilimitadas de desarrollo humano. Lo mismo pensamos, que una gran sinfonía no es menos "étnica" que una canción tribal africana. El reto de los músicos reside en su capacidad de identificar elementos étnicos y tribales en la música universal de todo tipo y de todas las latitudes; todo en función de fortalecer su nivel cultural y académico que finalmente sustentan su quehacer musical.

\section{PATRIMONIO MUSICAL POPULAR}

Entre las ideas relativas a algunas actividades de la música que es necesario emprender hoy en nuestro medio, podemos incluir algunas de las expectativas y propuestas que de por sí se desprenden del estudio de la naturaleza del hombre como hacedor de cultura. Esto es a través de la promoción de los patrimonios musicales populares y tradicio- nales a través de los cuales se podría:

- Señalar la función de las tradiciones orales en la construcción de las identidades, poniendo de manifiesto el rechazo contra los prejuicios étnicos y nacionalismos ciegos.

- Fomentar el impulso que permita la existencia y continuidad de las músicas tradicionales y populares, solicitando a la vez la declaración por parte de los entes del gobierno que dichas expresiones sean consideradas patrimonio cultural; y la urgencia de proceder a su conservación física.

- Proponer la creación de un Instituto de Música Tradicional y Popular que se encargue de promover y coordinar una red de estructuras que, con metodología y objetivos comunes, posean una dinámica de investigación, de creación y desarrollo del patrimonio. En el ámbito de dicho instituto se fomentaría la creación de redes tendientes a cubrir el inventario y catalogación, recuperación e investigación, conservación, transmisión, difusión, producción, comercialización, y comunicación de las culturas de tradición oral.

- Fomentar la constitución de nuevos centros de archivo y documentación, fonotecas, bibliotecas, videotecas, mediatecas, centros de formación de operadores culturales y museos, donde sea necesario. Así trabajar por el montaje de un sistema normalizado de descripción y de análisis documental que permita el intercambio de información y la elaboración de bancos de datos informáticos y telemáticos armonizados.

- Ayudar al conjunto de centros de documentación que administran los fondos de la música de tradición oral, a implantar y a adaptar ese sistema normalizado al fondo de archivos.

- Difundir lo más ampliamente posible 
todas las informaciones de orden legal, deontológico y técnico, relativas a la recogida, la gestión documental, la práctica y la explotación de la música de tradición oral.

- Potenciar los trabajos de recogidas de campo, realizar censos, colecciones bibliográficas y catálogos, superando con fundamento las limitaciones impuestas por las instituciones de promoción que solo promueven determinadas actividades condicionadas por un determinado concepto de "patrimonio".

- Promover actividades de estudio, conocimiento e interacción con otras realidades musicales (a través de festivales, tareas de documentación, encuentros e intercambios en todos los niveles: estudiantes, docentes, investigadores, promotores culturales, bibliotecarios, políticos.

Si consideramos algunos de los fenómenos que Néstor García Canclini (1991) observa en Latinoamérica: la crisis no solo personal de intelectuales y artistas sino de su papel como mediadores e intérpretes del cambio social; las migraciones a gran escala de los pueblos a las ciudades y la hibridación de las culturas, tal vez sea oportuno anticipar los dos tipos de investigaciones que este autor prevé en las sociedades posmodernas.

- Las que se ocupan de la modernización y el desarrollo cultural: nuevas tecnologías de telecomunicación y electrónica; producción, circulación y consumo de industrias culturales; formación técnica de recursos humanos para la administración cultural y recalificación de trabajadores en procesos de reconversión industrial, diagnósticos de conflictos interculturales en procesos de rápida transformación y en situaciones de frontera.
- Las que se dedican a modalidades tradicionales del desarrollo cultural, siempre que abarquen a conjuntos sociales cuantitativa o cualitativamente significativos: relaciones entre educación y cultura, cultura política y nuevas formas de hegemonía, mujer y familia; etnias indígenas mayoritarias, religiosidad popular, especialmente grupos de rápida expansión; artes, artesanías y otras manifestaciones folclóricas.

Finalmente, es posible aplicar algunas de estas áreas temáticas al ámbito de las culturas musicales y la reflexión sobre estas aplicaciones despierta un gran número de cuestiones que aguardan tanto nuestra respuesta como la de quienes se consideran involucrados en el mundo de la música. Los estudiantes saben que les espera una tarea complejísima que deberán asumir con lucidez, paciencia y realismo; ejercitando la reflexión y el diálogo interdisciplinario como cotidiana higiene epistemológica, para asumir las carencias que detecten en el desarrollo o las aplicaciones de la disciplina en el país, ciudad o región en que les toque trabajar. El tema de los proyectos y las expectativas en torno a la actividad interdisciplinaria de la música es un ámbito cuyo carácter impone a este texto un final abierto a la discusión, la crítica, pero fundamentalmente la propuesta.

\section{CONCLUSIONES}

Dado que la música genera realidades sociales dentro de la sociedad:

- La música, en cuanto medio de comunicación, contribuye a la construcción social de la realidad dentro de una sociedad dada, por lo que queda comprobada su alta capacidad de convocatoria.

- El arte musical está inmersa dentro de 
relaciones entre educación y cultura, cultura política y nuevas formas de hegemonía, mujer y familia; etnias indígenas mayoritarias, religiosidad popular, especialmente grupos de rápida expansión.

- Un tratamiento diacrónico aplicado a los diferentes niveles de análisis social fenomenal de la música nos daría la información pertinente sobre todo lo relacionado a los cambios e historia en las sociedades

- El correcto manejo del patrimonio tradicional musical de un pueblo puede contribuir, y contribuye, al aceleramiento del proceso y desarrollo social de los pueblos.

- El hombre como hacedor de cultura a través de la promoción de los patrimonios musicales podría orientar los usos y funciones de la música para reforzar la construcción de las identidades orientadas al manifiesto y rechazo contra los prejuicios étnicos y nacionalismos ciegos.

- Las prácticas del arte musical puede fomentar el impulso que permita la existencia y continuidad de las músicas tradicionales y populares, solicitando a la vez la declaración por parte de los entes del gobierno que dichas expresiones sean consideradas patrimonio cultural; y la urgencia de proceder a su conservación física.

\section{REFERENCIAS BIBLIOGRÁFICAS}

Martí Í Pérez, J. (2000). Más Allá del Arte. Balmes, España: Deriva Editorial.

García Canclini, N. (1977). Arte Popular y Sociedad en América Latina. México: Editorial Grijalbo.

García Canclini, N. (1989). Culturas Hibridas. Estrategias para entrar y salir de la Modernidad. México: Editorial Grijalbo.

Méndez, L. (2009). Antropología del campo artístico. Del arte primitivo al arte contemporáneo. Madrid, España: Editorial Síntesis, S.A.

Merriam, A. P. (1964). The Anthropology of Music. By Alan P. Merriam. Printed in the United States of America.

Morín, E. (1997). Introducción al Pensamiento Complejo. Barcelona, España: Editorial Gedisa. Traducción al español de Marcelo Pakman. Título Original: Introduction a la Pensée Complexe. Primera Edición 1990. ESF Editeur. París, Francia.

Radcliffe-Brown, A. R. (1972). Antropología social - Estructura y Función en Sociedades Primitivas". Barcelona, España: Editorial Península. Título Original: "The social anthropology - Structure and Function in Primitive Society" ()Adam Kuper, 1952. Printed in the United States of America. 